\title{
Living their passion for upliftment - RuDASA award winners
}

From celebrating the work of a rare rural audiologist to lauding the selfless lifetime achievements of a veteran community change-agent, the Rural Doctors' Association of South Africa (RuDASA) awards at its 20th annual conference in Grahamstown on 8 August showcased vocation-driven talent.

A near-gold-standard audiology service set up over the past 3 years at the remote but historically award-winning Eastern Cape Zithulele Hospital won the Rural Rehabilitation Worker of the Year for University of KwaZulu-Natal audiology graduate Lineo Lecheko. Enhancing Zithulele's multidisciplinary approach, Lecheko's screening of multidrug-resistant tuberculosis patients has led to vastly improved local hearing outcomes. Patients newly fitted with hearing aids (rare in rural areas) regularly travel long distances just to bring homegrown gifts to thank her for helping transform their worlds. Her initial impact drew the attention of the provincial treasury which boosted her work with more than ZAR1 million of audiology equipment and facilitated the placement of an audiology community service assistant.

\section{Epitomising knowledge- to-practice}

RuDASA's Rural Doctor of the Year for 2016 was Dr Nomlindo Makubalo, who started out by winning a bursary to add an $\mathrm{MB} \mathrm{ChB}$ degree to her medical technology diploma before qualifying and gaining experience in paediatrics, genetics and advanced health management. As the Eastern Cape's District Clinical Specialist Team leader, she co-ordinates child healthcare and collegial training. The citation lauds her major contribution to Child Programme Improvement Plans (PIP), the procurement of critical hospital equipment and high-care beds, new neonatal units in district hospitals, HIVpositive patient tracing, and establishing vital protocols such as the Helping Babies Breathe, Management of Small and Sick

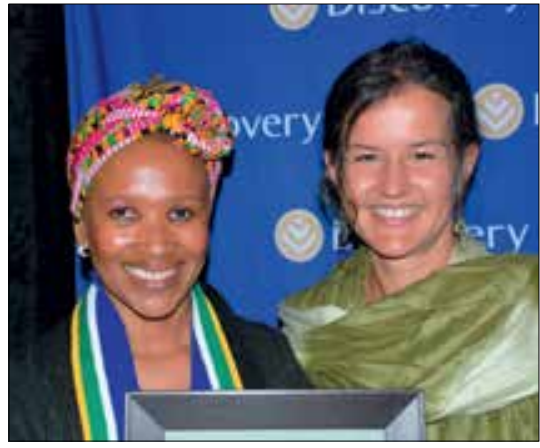

Award-winning audiologist Lineo Lecheko, with Maryke Bezuidenhout, Rural Rehab South Africa chair.

Neonates and Emergency Triage Assessment and Treatment. Her training of doctors and nurses in early identification of children with genetic conditions has boosted outcomes in the province, while emergency medical service waiting times have improved markedly under her leadership in the Nelson Mandela Bay and Sarah Baartman districts.

The prestigious 2016 RuDASA Lifetime Achievement Award went to the sprightly 35-year missionary veteran CEO of Mseleni Hospital in KwaZulu-Natal, Dr Victor Fredlund, age 60, whose leadership and compassion have impacted on virtually every sphere of life in the district. From building toilets to teaching basic sanitation, pumping water from nearby Lake Sibayi to reticulate through the hospital and surrounding community, Fredlund has also helped buy community tractors for ploughing, set up market and subsistence gardens, built classrooms, a 1000 -seater community hall, a computer centre and sports facilities, facilitated a local market and launched several youth employment projects. His upliftment includes the Lulisanda Kumtwana project, which at one stage had 3000 registered orphans under its care, many of them AIDS orphans. He pioneered the concept of academic scholarships for rural children, the local teaching of maths and science and the bursary-linked return of healthcare workers to their own communities. Together with his equally tireless wife Rachel, he continually hosts destitute and homeless local children in the wooden home theybuilt, and has sponsored the living expenses and school/university fees of countless others over the years. Accepting the award on his behalf, Mseleni senior medical officer Dr Kobus Viljoen said the Fredlund household overnight was a mix of foreign students, volunteers and children - often with Fredlund entertaining them on his trusty guitar. A fearless surgeon with a penchant for cardiology, he had conducted 'every ectomy and otomy in the book, and regularly did hernia repairs, hysterectomies and total hip replacements, while his clinical brag list included three full-term extrauterine deliveries (incidence 1 in 30 000). He summed up Fredlund by quoting former US president, Harry Truman: 'It's amazing what you can accomplish if you don't mind who gets the credit.'

Together with his equally tireless wife Rachel, he continually hosts destitute and homeless local children in the wooden home they built, and has sponsored the living expenses and school/ university fees of countless others over the years.

The Rural Nurse of the Year award went to Sister Charlotte Stemmet, whose versatile mobile clinic design went into production in the Western Cape recently, while Prince Maletje Maleka won the Clinical Associate of the Year award for his 'Street Medicine' project in Tshwane.

\section{Chris Bateman \\ chrisb@hmpg.co.za}

S Afr Med J 2016;106(10):959.

DOI:10.7196/SAMJ.2016.v106i10.11436 